\title{
"A Rare Case Report: Carcinoma Esophagus in 12-year-old Girl with Unknown Etiology"
}

\author{
Pawan Kumar*, Rohitashwa Dana, Prashant Dadhich, Vipul Mehta and Manish Kumar Chaturvedi \\ Department of Radiation Oncology, SMS Medical College and Hospital, India
}

Submission: June 01, 2019; Published: June 13, 2019

*Correspondence Author: Pawan Kumar, Department of Oncology, SMS Medical College and Hospital, PIN Code- 302004, Jaipur, Rajasthan, India

\begin{abstract}
A 12-year-old girl with moderately differentiated squamous cell carcinoma of the lower esophagus is reported because of its rare presentation in this age group. The patient was presented with vomiting and progressive dysphagia with associated weight loss for 3 months. We could not find any known etiological factors association with this patient. The case was treated with External Beam Radiotherapy by 3-Dimensional Conformal Radiotherapy (3DCRT) technique with excellent immediate response.
\end{abstract}

Keywords: Squamous cell Carcinoma; Esophagus; External beam radiotherapy; 3-Dimensional Conformal Radiotherapy

\section{Introduction}

Esophageal malignancies are rare in younger age group and extremely rare in children and adolescents [1], with only few case reports till date [2-6]. It is commonly seen in the sixth, seventh, and eighth decades of life [1]. The possible reason behind its rarity in younger age was due to a long latent period for carcinogenesis by predominantly environmental produced etiological factors [7]. There was no mention of etiological or environmental risk factors in the majority of these reported cases, and therefore, the pathogenesis of the condition is still unknown. Herein, we report a case of squamous cell carcinoma involving the lower-third of the esophagus in a 12-year-old girl because of its rare presentation in the teenage group.

\section{Case Report}

A 12-year-old girl child presented with dysphagia and severe episodes of vomiting following a meal since last 3 months that was initially with solid food, which progressively increased to semisolid diet and she was unable to swallow even liquids since last 2 weeks before presenting to hospital. Her dysphagia was not associated with any throat or chest pain during deglutition and she had no history of ingestion of any corrosive substance in past. She was 4 th born child to her mother and developed all milestones on time and vaccinated with all routinely prescribed vaccines at government hospital on prescribed schedule. She is living in urban slum area since birth. She was having history of eating sand and charcoal (pica) for around 5-6 years in early childhood till she attains the age of 9 years. There was no history of any esophageal or gastrointestinal malignancy in anyfirst- or second-degree family member and no known familial or genetic disorder. Except for her thin built and pallor signs, systemic examination was unremarkable. She lost around $6 \mathrm{~kg}$ weight in last 3 months. There was no keratinization of her palms or soles to suggest tylosis. Except for low haemoglobin level (7.6 gm/ $\mathrm{dl}$ ), other laboratory investigations and chest radiographs were within normal limits.

Upper GI endoscopy shows a large circumferential growth at lower end starting at $28 \mathrm{~cm}$ from incisor with marked luminal narrowing. A biopsy from the growth revealed a moderatelydifferentiated squamous cell carcinoma. A contrast-enhanced computed tomogram (CECT) scan of the chest and abdomen reported an irregular mucosal thickening $(20 \mathrm{~mm})$ of lower end of esophagus involving gastro esophageal junction (Length of involved segment was $6 \mathrm{~cm}$ ). There was no any other evidence of distant metastases to any other site. At the time of initial presentation to hospital she was not able to take anything orally and not possible to insert Ryle's tube for feeding due to complete obstruction of esophageal lumen by growth, so feeding jejunostomy tube was inserted for feeding after proper counselling and informed written consent from her relatives. Thereafter case was discussed in our institutional tumor board, where her family was counselled for available treatment options either surgical resection or concurrent chemoradiotherapy with all side effects and benefits of both modalities. Patient's relative refused for surgical intervention so concurrent chemoradiotherapy was advised by tumor board. 


\section{Cancer Therapy \& Oncology International Journal}

After gone through the all essential initial workup she was planned for external beam radiotherapy (EBRT) with concurrent weekly cisplatin $30 \mathrm{mg} / \mathrm{m} 2$ with best supportive care. EBRT was delivered by 3-dimension conformal radiotherapy (3DCRT) technique at Linear accelerator center, SMS Hospital Jaipur. She was treated with 54 Gy in 27 fractions at 2 Gy per fraction dose with added 1 more fraction for gap correction due to prolongation of treatment time by some technical errors in machine during treatment. She tolerated treatment very well with good initial response rate and started oral liquids after 4-5 initial fractions and started taking semisolid food after delivery of 8 fractions. She was discharged from hospital after completion of prescribed treatment.

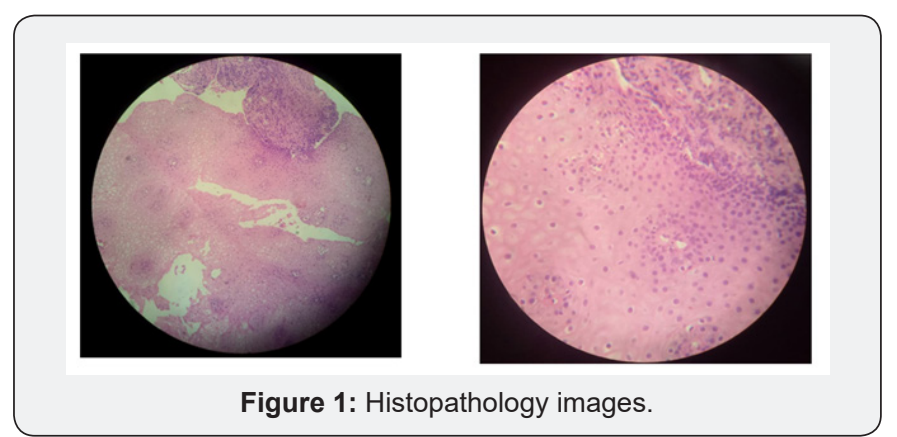

On first follow up visit after 1 month of completion of treatment she was fine except mild intermittent pain in chest wall and gained $5 \mathrm{~kg}$ of body weight. All routine blood investigation and general physical examination are within normal limits (Figure 1). Feeding jejunostomy tube was removed after 1 month of completion of EBRT. After completion of 3-month post radiotherapy she was investigated with upper GI endoscopy and CT scan of chest and abdomen which was not showing any sign of residual or metastatic disease. On continuous follow up for 6 months she was remains symptom free and there was no sign of any recurrence or metastatic disease.

\section{Discussion}

The mean age at diagnosis of esophageal cancer is in range of 27 - 87 years. Beyond 40 years incidence of both squamous cell and adenocarcinoma carcinoma of the esophagus rises with each decade of life [6]. Esophageal malignancy rarely occurs in childhood because it develops by chronic irritation from a wide variety of known environmental factors and chronic reflux of gastric contents, which requires a long latent period of around 15-20 years for carcinogenesis [8]. Only few cases of esophageal malignancies in children were reported in literature so far [26]. Interestingly, esophageal carcinoma in early age has been reported more frequently from India than any other part of world. More than 10 cases are reported in literature so far from this part of the world. The youngest patient reported so far was an 8-year old Indian girl with esophageal carcinoma in the middle third of the esophagus with lung metastases reported in 1980 [2].
Carcinoma of the esophagus is commonly seen in some areas of Central Asia, China, South Africa, some parts of India, and Iran [9-14]. It is one of the leading causes of death in these regions. The dramatic diversity of incidence within these discrete geographical areas, between the sexes, among various ethnic groups and among high- and low-risk areas suggests a predominant role for environmental factors in esophageal carcinogenesis. A general background status of nutritional deficiencies, either due to chronic alcohol abuse, poverty and/ or lack of adequate food supply often co-exists. Carcinogens may be derived from tobacco, consumption of moldy foods, excessive use of spices, or certain food specialties in different cultures. The prevalence of disease was also found to be positively associated with the consumption of extremely hot beverages, prevalence of esophagitis among siblings, family history of esophageal cancer and use of cottonseed oil [15]. Various studies from endemic areas suggested that environmental carcinogens like tobacco, alcohol, foods with certain spices; nutritional deficiencies such as low level of riboflavin, retinol and zinc; exposure to $\mathrm{N}$-nitrosamines and fungal contamination of foods had predominant role in esophageal malignancy development. Tylosis, achalasia, esophageal diverticula, lye stricture and Plummer-Vinson syndrome are considered as premalignant conditions for esophageal carcinoma $[7,8]$. But none of these conditions have been reported to cause the esophageal carcinoma in childhood.

Our patient is a 12-year-old girl belonging to low socioeconomic class, had no any significant above-mentioned risk factors, although she was having history of pica early childhood and her low weight for age reveals her nutritional deficient status that might be a causative factor but not proven. The factors commonly implicated in the pathogenesis of carcinoma of the esophagus such as alcoholism, post-radiation, chronic infection, tobacco, a history of lye burns, or achalasia were not seen in our patient. Also, we could not find any familial risk factors or premalignant conditions in our patient.

The clinical presentation of esophageal carcinoma in children are similar to those in adults and include dysphagia, regurgitation, weight loss, chest pain, hematemesis, and occasionally a palpable mass. These symptoms are nonspecific and may be indicative of other conditions in children such as chronic retention of foreign body in the esophagus, gastroesophageal reflux and its complications, achalasia, or post-corrosive strictures. The important finding in the present case was a large circumferential exophytic growth at lower part of esophagus on upper gastro intestinal endoscopy was found at the time of initial presentation. The biological behaviour or malignant tumors of the esophagus in children or teenagers is similar to adults with frequent widespread metastatic disease commonly involving the lung, liver, or mediastinal lymph nodes. In the present case there was nothing to suggest any secondary deposits in the body elsewhere. The management of the disease depends on the stage, and equally good results are reported with surgery and radiotherapy for operable disease. Also, the outcome 


\section{Cancer Therapy \& Oncology International Journal}

depends on the stage of the disease and is not influenced by age. Our patient is treated with radiotherapy after declaring surgically unfit and shown an excellent immediate response.

Our patient is enjoying excellent health and there is no evidence of recurrence. We have not been able to associate her disease with any etiological or environmental factor known to predispose the malignancy. She also did not have any of the known precancerous lesions that could have contributed to her disease. Further detailed genetic evaluation is needed to see the any genetic correlation of esophageal malignancy in this case.

\section{Conflict of Interest}

None.

\section{References}

1. Mori M, Ohno S, Tsutsui S (1990) Esophageal cancer in young patients. Ann Thorac Surg 49: 284-286.

2. Soni NK, Chatterji P (1980) Carcinoma of the oesophagus in an eightyear-old child. J Laryngol Otol 94(3): 327-329.

3. Kinnman J, Shin HI, Wetteland P (1968) Carcinoma of the oesophagus after lye corrosion. Acta Chir Scand 134(6): 489-493.

4. Allam AR, Fiaz M, Fazili FM, Khawaja FI, Sultan A (2000) Esophageal carcinoma in a 15-year-old girl: A case report and review of the literature. Ann Saudi Med 20: 261-265.

5. Aryya NC, Lahiry TK, Gangopadhyay AN, Asthana AK (1993) Carcinoma of the esophagus in childhood. Pediatr Surg Int 8(3): 251-252.

6. Shahi UP, Sudarsan, Dattagupta S, Singhal S, Kumar L, et al. (1989) Carcinoma esophagus in a 14-year-old child: Report of a case and review of literature. Trop Gastroenterol 10(4): 225-228.

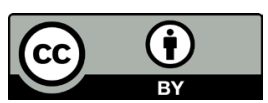

This work is licensed under Creative Commons Attribution 4.0 License DOI: 10.19080/CTOIJ.2019.14.555882
7. Li MX, Cheng SJ (1984) Etiology of carcinoma of the esophagus. In: Huang GJ, Kai WY, editors. Carcinoma of the esophagus and gastric cardia. Springer-Verlag, New York, USA, p. 25-51.

8. Hongo M, Nagasaki Y, Shoji T (2009) Epidemiology of esophageal cancer: orient to occident. Effects of chronology, geography and ethnicity. J Gastroenterol Hepatol 24(5): 729-735.

9. Days N, Munoz N (1982) Esophagus. In: Schottemfeld D, Fraumeni J, (eds), Cancer epidemiology and prevention. WB Saunders Co., Philadelphia, USA, pp. 596-623.

10. Jaskiewicz K, Marasas WFO, Van der Walt FE (1987) Oesophageal and other main cancer patterns in four districts of Transkei (1981-1984) S Afr Med J 72(1): 27-30.

11. Lu JB, Yang WX, Liu JM, Li YS, Qin YM, et al. (1985) Trends in morbidity and mortality for esophageal cancer in Linxian County (1959-1983). Int J Cancer 36(6): 643-645.

12. Siddiqi M, Preussmann R (1989) Esophageal cancer in Kashmir: an assessment. J Cancer Res Clin Oncol 115(2): 111-117.

13. Khuroo MS, Zargar SA, Mahajan R, Banday MA (1992) High incidence of oesophageal and gastric cancer in Kashmir in a population with special personal and dietary habits. Gut 33(1): 11-15.

14. Sadeghi A, Behmard S, Shafiepoor H (2000) Cancer of esophagus in Southern Iran. Cancer 40: 841-5. Allam et al. Annals of Saudi Medicine 20(3-4).

15. Chang Claude JC, Wahrendorf J, Liang QS, Rei YG, Muñoz N, et al. (1990) An epidemiological study of precursor lesions of esophageal cancer among young persons in a high-risk population in Huixian, China. Cancer Res 50(8): 2268-2274.

\section{Your next submission with Juniper Publishers will reach you the below assets}

- Quality Editorial service

- Swift Peer Review

- Reprints availability

- E-prints Service

- Manuscript Podcast for convenient understanding

- Global attainment for your research

- Manuscript accessibility in different formats

( Pdf, E-pub, Full Text, Audio)

- Unceasing customer service

Track the below URL for one-step submission https://juniperpublishers.com/online-submission.php 